\title{
$O$ efeito de fórmulas nutricionais utilizadas no tratamento de crianças com alergia à proteína do leite de vaca: uma revisão sistemática
}

The effect of nutritional formulas used in the treatment of children with cow millk protein allergy: a systematic review

El efecto de las fórmulas nutricionales utilizadas en el tratamiento de niños con alergia a las proteínas de leche de vaca: una revisión sistemática

\section{Resumo}

Introdução: A literatura tem evidenciado um aumento na prevalência de crianças com alergia à proteína do leite de vaca (APLV) e o seu tratamento consiste em retirar esse alimento e seus derivados da dieta e na substituição por fórmulas à base de proteína isolada de soja ou de fórmulas hidrolisadas. Objetivo: Avaliar os efeitos do uso de fórmulas nutricionais em crianças com APLV. Metodologia: A busca e seleção dos artigos seguiram as recomendações do Preferred Reporting Items for Systematic Reviewsand Meta-Analyses (PRISMA), utilizou-se as palavras-chaves: "milk hypersensitivity”, "food hypersensitivity, hydrolyzed", "vegetal protein", "vegetal protein", "soy bean proteins" em combinação ou isoladas, nas bases de dados Pubmed, Scopus e Science direct. Resultados: Nove artigos foram incluídos, sendo seis ensaios clínicos, um estudo de coorte, um estudo observacional e um estudo multicêntrico. Foram testadas: fórmula de proteína extensamente hidrolisada, fórmula à base de aminoácidos e fórmula à base de soja. Sendo que em 3 estudos as fórmulas de proteína extensamente hidrolisada e a de aminoácidos foram associadas com probióticos Lactobacillus rhamnosus e tiveram 2 estudos associados com simbióticos. Conclusão: Todos os tipos de fórmulas analisadas contribuíram para melhora nos sintomas relacionados a APLV, sendo os melhores resultados observados para as fórmulas com probióticos. No entanto, são necessários mais estudos que avaliem os efeitos dos probióticos adicionados em fórmulas nutricionais para o tratamento de APLV, seu potencial precisa ser melhor avaliado, principalmente em estudos a longo prazo.

Palavras-chave: Hipersensibilidade a leite; Alimentos de soja; Hipersensibilidade alimentar.

\footnotetext{
Abstract

Introduction: The literature has shown an increase in the prevalence of children with allergy to cow's milk protein (APLV) and their treatment consists of this food and its dietary derivatives and its replacement by formulas based on
} 
isolated soy protein or formulas hydrolyzed. Objective: To evaluate the effects of using nutritional formulas in children with APLV. Methodology: The search and selection of articles followed the recommendations of the Preferred Reporting Items for Systematic Reviews and Meta-Analyses (PRISMA), using the keywords: "milk hypersensitivity", food hypersensitivity, hydrolyzed", "vegetable protein", "vegetable protein", "soy bean proteins" in combination or alone, in Pubmed, Scopus and Science direct databases. Results: Nine articles were included, including six clinical trials, a cohort study, an observational study and a multicenter study. Were tested: extensively hydrolyzed protein formula, amino acid-based formula and soy-based formula. In 3 studies, extensively hydrolyzed protein and amino acid formulas were associated with probiotics Lactobacillus rhamnosus. and there were 2 studies associated with symbiotics. Conclusion: All types of formulas analyzed contributed to improvement in symptoms related to APLV, with the best results observed for formulas with probiotics. However, further studies are needed to assess the effects of added probiotics in nutritional formulas for the treatment of APLV, its potential needs to be better evaluated, especially in long-term studies.

Keywords: Milk hypersensitivity; Soy foods; Food hypersensitivity.

\section{Resumen}

Introducción: La literatura ha demostrado un aumento en la prevalencia de niños con alergia a la proteína de la leche de vaca (APLV) y su tratamiento consiste en este alimento y sus derivados dietéticos y su sustitución por fórmulas a base de proteína de soja aislada o fórmulas hidrolizadas. Objetivo: Evaluar los efectos del uso de fórmulas nutricionales en niños con APLV. Metodología: La búsqueda y selección de artículos siguió las recomendaciones del Preferred Reporting Items for Systematic Reviews and Meta-Analysis (PRISMA), utilizando las palabras clave: "hipersensibilidad a la leche", "hipersensibilidad alimentaria, hidrolizada", "proteína vegetal", "vegetal protein", "proteínas de soja"en combinación o solas, en las bases de datos directas de Pubmed, Scopus y Science. Resultados: Se incluyeron nueve artículos, incluidos seis ensayos clínicos, un estudio de cohorte, un estudio observacional y un estudio multicéntrico. Fueron probados: fórmula de proteína ampliamente hidrolizada, fórmula a base de aminoácidos y fórmula a base de soja. En 3 estudios, las fórmulas de aminoácidos y proteínas ampliamente hidrolizadas se asociaron con probióticos Lactobacillus rhamnosus y hubo 2 estudios asociados con simbióticos. Conclusión: Todos los tipos de fórmulas analizadas contribuyeron a la mejora de los síntomas relacionados con APLV, con los mejores resultados observados para las fórmulas con probióticos. Sin embargo, se necesitan más estudios para evaluar los efectos de los probióticos agregados en las fórmulas nutricionales para el tratamiento del APLV, su potencial debe evaluarse mejor, especialmente en estudios a largo plazo.

Palabras clave: Hipersensibilidad a la leche; Alimentos de soja; Hipersensibilidad a los alimentos.

\section{Introdução}

Alergias e intolerâncias alimentares são problemas com prevalência crescente em todo o mundo, constituindo importante problema de saúde pública que afeta crianças (Manuyakorn \& Tanpowpong, 2019). A alergia a proteína do leite de vaca (APLV) é uma das alergias alimentares mais comuns em bebês e crianças pequenas (Flim \& Sicherer, 2019). Ela se caracteriza como uma resposta imunomediada às proteínas do leite de vaca, sendo relacionada à sua exposição (Savage \& Johns, 2015; Venter \& Arshad, 2011). No leite, os principais responsáveis por essas manifestações são as proteínas do seu soro (a ß-lactoglobulina sendo a mais abundante) e as caseínas (Boettcher \& Crowe, 2013).

A incidência de APVL na primeira infância é de cerca de 2-3\% nos países desenvolvidos. Aproximadamente 50-70\% têm sintomas cutâneos, 50-60\% sintomas gastrointestinais e 20-30\% sintomas respiratórios (Host \& Halken, 2014). Esse tipo de alergia pode ocorrer, inclusive, em crianças alimentadas exclusivamente com leite materno. Sendo que a incidência neste grupo é baixa, cerca de $0,5 \%$. Sua apresentação clínica é geralmente leve a moderada, pois a concentração da proteína do leite de vaca no leite humano é 100.000 vezes menor do que no leite de vaca (Vandenplas \& Guidelines, 2007).

Segundo Barros et al., (2017) a APLV pode ou não ser mediada por imunoglobulina (IgE). Essas duas formas podem produzir sintomas diferentes. As reações mediadas por IgE são reações imediatas (2 horas após a ingestão de leite) que se caracterizam como reações tipicamente mais persistentes com o passar dos anos e geralmente mais graves. Já as não mediadas, não produzem anticorpos IgE específicos e os sintomas são tardios (horas ou dias após a ingestão de leite).

Seu tratamento consiste na retirada do leite de vaca e seus derivados da dieta e na sua substituição por fórmulas à base de proteína isolada de soja ou de fórmulas hidrolisadas, a depender de critérios clínicos (Aguiar, et al., 2013; Kemp et al., 2008; Reche, et al., 2010). 
Os lactentes com APLV que não estejam sendo amamentados devem receber fórmulas sem a proteína intacta do leite de vaca, que podem ser extensamente hidrolisadas à base da proteína do leite de vaca, dieta com aminoácidos livres ou de proteína isolada de soja (somente para crianças maiores de seis meses e sem manifestação gastrintestinal). Para lactentes ainda em aleitamento, a nutriz deve excluir produtos lácteos da sua alimentação (Vandenplas, De Greef \& Hauser, 2014).

O uso de hidrolisados proteicos é prioritário como dieta de substituição para crianças com APLV, podendo contribuir para controle dos sintomas, manutenção do estado nutricional e melhora na tolerância futura a proteína do leite de vaca. As fórmulas de aminoácidos devem ser restritas aos casos de intolerância aos extensamente hidrolisados, alergias múltiplas ou quadros clínicos graves, com comprometimento nutricional intenso (Aguiar, 2013). Somado a isso, segundo o Consenso Brasileiro sobre Alergias (2018) alguns estudos apontam que a suplementação com probióticos em pacientes com APLV pode atuar na redução de sintomas.

A utilização dessas fórmulas alimentares pelos lactentes tem o objetivo de evitar o desencadeamento dos sintomas, a progressão da doença e evitar a piora da manifestação alérgica, proporcionando adequados crescimento e desenvolvimento na criança (Caetano, et al., 2010; Fiocchi, et al., 2010). Essas manifestações podem aumentar as necessidades de energia através da pele, inflamação gastrointestinal ou respiratória, padrões de sono interrompidos e absorção reduzida dos principais nutrientes (Dupont, et al., 2011).

Assim o objetivo dessa revisão sistemática descrever os efeitos de diferentes fórmulas nutricionais em crianças com APLV.

\section{Metodologia}

Dentre os métodos de revisão de literatura, o presente estudo adotou a modalidade sistemática e a pergunta norteadora foi definida com o auxílio da estratégia PICO (patient, intervention, comparison and outcomes). P: Crianças com APLV, I: Uso de fórmulas, C: Crianças com APLV que passaram usar fórmulas de proteínas extensamente hidrolisadas, a base de aminoácidos e proteína vegetal, O: Efeito das fórmulas nos sintomas da APLV.

A busca de artigos foi realizada de forma independente, por três autores (CMC, RCM, MMB). A coleta de dados ocorreu durante os meses de abril e maio de 2021 e foi norteada pela seguinte pergunta: Qual o efeito de fórmulas de proteínas extensamente hidrolisadas, a base de aminoácidos e proteína vegetal no tratamento de crianças com alergia à proteína do leite de vaca?

Foram empregados os Descritores em Ciências da Saúde (DeCS): milk hypersensitivity, food hypersensitivity, hydrolyzed vegetal protein, vegetal protein, soybean proteins, (Hipersensibilidade a Leite, Proteína Hidrolisada Vegetal, Proteínas de Soja). A estratégia de busca utilizada combinou dois ou mais descritores por meio do conector 'AND' no campo 'descritor de assunto'.

A partir daí, foi realizada a pré-seleção dos artigos relacionados ao tema por meio da leitura criteriosa dos títulos e resumos, a fim de verificar a adequação dos artigos após os critérios de elegibilidade, aqueles artigos selecionados foram submetidos a leitura de texto completo, e por fim, selecionados de acordo com os critérios de inclusão e exclusão. Para a análise dos artigos, foi realizada a leitura minuciosa dos mesmos, constatando sua relação ao objetivo do presente trabalho.

Os critérios de inclusão adotados foram: ensaios clínicos controlados randomizados, duplo-cego, observacionais de coorte, ser artigo e ter sido publicado entre os anos de 2011 e 2021 nas bases de dados científicas Scopus, Pubmed e Science Direct, ter sido divulgado em língua portuguesa, inglesa ou espanhola; estar disponível na íntegra; apresentar em seus resultados fatores significativamente associados à utilização de fórmulas e aos sintomas relacionadas ao ALPV. 
Seguindo critérios de exclusão: foram desconsideradas publicações referentes a teses, dissertações, resumos de congressos, anais, editoriais, comentários e opiniões, artigos de revisão, estudos que incluíssem em sua amostra crianças com idade superior 5 anos.

Para detalhamento dos estudos, foram coletadas informações relevantes, entre as quais destacam-se: autores, ano de publicação, tamanho da amostra e idade da população estudada, tipo de fórmula e duração da administração da fórmula. A figura 1 apresenta o fluxograma para seleção dos artigos que foram abordados na revisão sistemática.

Os artigos pré-selecionados foram lidos na íntegra e aqueles selecionados para a revisão foram analisados a partir de do instrumento Critical Apppraisal Skills Programme (CASP) - Programa de habilidades em leitura crítica, integrante do Public Health Resource Unit (PHRU), elaborado pela Universidade de Oxford, em 1993 (London, 2002). O instrumento foi eleito devido à proposta de análise objetiva, sistemática e de fácil entendimento. Este consiste em 10 itens (máximo 10 pontos), abrangendo: 1) objetivo, 2) adequação metodológica, 3) apresentação dos procedimentos teóricos e metodológicos, 4) seleção da amostra, 5) procedimento para a coleta de dados, 6) relação entre o pesquisador e pesquisados, 7) consideração dos aspectos éticos, 8) procedimento para a análise dos dados, 9) apresentação dos resultados e 10) importância da pesquisa. Os estudos foram classificados de acordo com as seguintes pontuações: 6 a 10 pontos - boa qualidade metodológica e viés reduzido; e mínima de 5 pontos - qualidade metodológica satisfatória, porém com risco de viés aumentado. Foram considerados apenas os artigos classificados de 6 a 10 pontos de evidência.

Figura 1. Fluxograma do procedimento metodológico para busca de artigos.

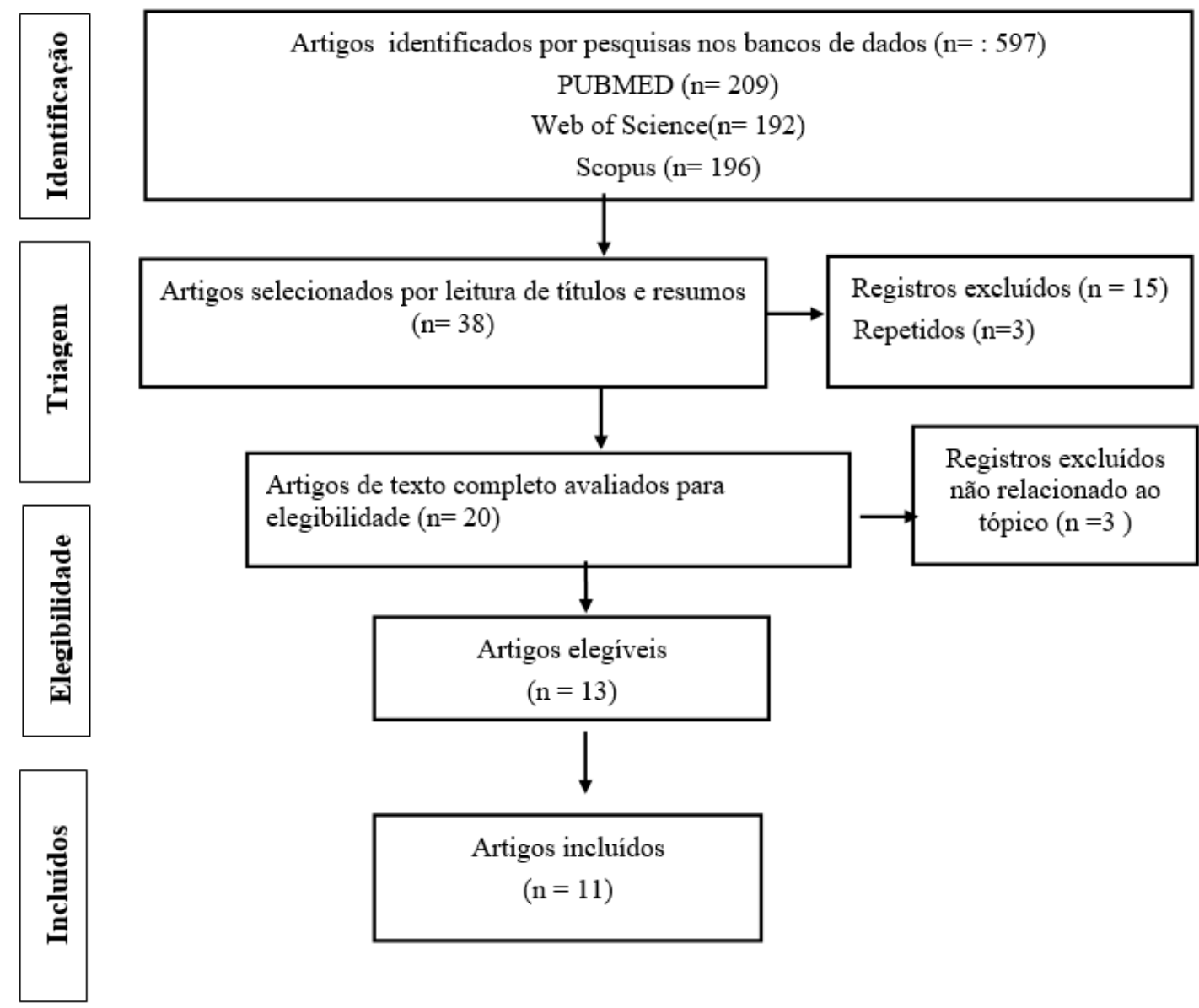

Fonte: Autores (2021). 


\section{Resultados}

Foram encontrados 597 artigos na pesquisa realizada nas três bases científicas mencionadas. Destes, 11 artigos foram incluídos nesta revisão sistemática, dos quais 5 foram recuperados a partir do Scopus, 6 Pubmed e 0 Science direct.

Foram encontrados 8 estudos clínicos, 1 estudo de coorte, 1 estudo observacional e 1 estudo multicêntrico. Os estudos foram realizados em 8 países diferentes e foram conduzidos com crianças na faixa etária de um mês até 5 anos, sendo que tamanho da amostra variou de 25 até 470 crianças. As fórmulas testadas foram: fórmula de proteína extensamente hidrolisada, fórmula à base de aminoácidos, caseína e fórmula à base de soja. De 11 analises, 5 demostraram o uso da fórmula extensamente hidrolisada, 5 a base de aminoácidos e 3 extensamente hidrolisada a base de caseína. Sendo que em 6 estudos as fórmulas de proteína extensamente hidrolisada e à de aminoácidos ou caseína foram associadas com probióticos Lactobacillus rhamnosus e tiveram 3 estudos associados com simbióticos (prebióticos de frutooligossacarídeos e cepa probiótica ou Lactobacillus paracasei) e 2 usaram apenas fórmula extensamente hidrolisada à base de caseína e um a base de aminoácido.

Os estudos selecionados avaliaram o efeito do uso dessas fórmulas em crianças com APLV e diversos parâmetros foram verificados, entre eles: sintomas alérgicos, microbiota intestinal, surgimento de outras alergias alimentares e resposta ao desenvolvimento de tolerância oral ao leite de vaca. A tabela 1 apresenta os dados referentes ao efeito do uso de fórmulas em crianças com APLV.

Paparo, et al., (2019) compararam bebês com APLV de 2 a 4 meses que passaram a usar fórmula extensamente hidrolisada contendo Lactobacillus rhamnosus ou fórmula à base soja, durante 12 meses. Os autores observaram que houve uma modulação mais forte dos mecanismos epigenéticos associados a uma tendência de maior taxa de aquisição de tolerância imunológica em crianças tratadas com a fórmula extensamentehidrolisada contendo Lactobacillus rhamnosus. Semelhante a isso, Scalabrin et al., (2017) também associaram o uso de fórmula extensamente hidrolisada com e sem Lactobacillus rhamnosus (LGG) ou fórmula à base de aminoácidos com LGG, durante 12 meses. As fórmulas com Lactobacillus rhamnosus foram associadas a crescimento e desenvolvimento normais das crianças e tiveram maior segurança à longo prazo até os 5 anos de idade.

Canani, et al., (2016) compararam bebês com APLV que passaram usar fórmula extensamente hidrolisada com e sem probiótico Lactobacillus rhamnosus, durante 36 meses. A fórmula com probióticos foi mais eficaz na prevenção da ocorrência de outras alergias alimentares e ajudou acelerar o desenvolvimento de tolerância oral em crianças APLV.

O estudo conduzido por Convidad \& Fuller (2019) verificaram bebês com APLV que passaram utilizar fórmula extensamente hidrolisada com Lactobacillus rhamnosus ou fórmula com soro do leite, durante 24 meses e constataram que a fórmula com Lactobacillus rhamnosus. retardou a marcha alérgica observada em crianças alérgicas ao leite de vaca.

O estudo de Candy, et al., (2018) avaliou durante 8 semanas o uso de fórmula à base de aminoácidos associada com simbióticos (prebióticos de frutooligossacarídeos e cepa probiótica Bifidobacterium breve (M-16V) ou fórmula à base de aminoácidos sem simbióticos. A fórmula à base de aminoácidos incluindo simbióticos melhorou a microbiota fecal de bebês com suspeita de APLV.

Harvey, et al., (2017) compararam duas fórmulas à base de aminoácidos com e sem simbióticos, durante 16 semanas e verificaram que ambas as fórmulas foram eficazes em fornecer um estado mineral (cálcio, fósforo, cloreto, sódio, potássio, magnésio e ferro (ferritina) adequado para bebês com APLV.

O estudo de Vanderhoof et al. (2016) foi observacional e acompanhou crianças com APLV que passaram a utilizar fórmula infantil à base de aminoácidos, durante 12 semanas e foi observado melhora para muitos sintomas alérgicos, como diminuições na gravidade da dermatite atópica. 
Inuo, et al., (2018) compararam durante 16 semanas três tipos de fórmulas: fórmula extensamente hidrolisada, fórmula à base de aminoácidos, fórmula de leite de vaca normal. A imunoterapia oral envolvendo a ingestão de fórmula de leite de vaca extensamente hidrolisado melhorou a tolerância ao leite de vaca em crianças com alergia a proteína do leite de vaca.

Dupont, et al., (2016) acompanharam bebês com APLV que passaram a utilizar fórmula extensamente hidrolisada como fonte de proteína e é engrossada com um complexo patenteado contendo fibras (0,5 g/100 ml), compostas principalmente de pectina. Os sintomas digestivos foram resolvidos ou melhorados a partir do dia 14 para 83,3\% dos pacientes e para $100 \%$ dos pacientes em 45 dias. Foi observado a normalização do crescimento dos bebês de acordo com os padrões da OMS.

Segundo Vandenplas, (2014) a regurgitação diminuiu significativamente em todos os grupos. Em comparação com a fórmula infantil padrão, um hidrolisado extensivo (caseína) demonstrou aumentar o esvaziamento juntamente com a normalização da consistência das fezes e o desenvolvimento dos parâmetros antropométricos foi normal.

Tabela 1. Características dos estudos incluídos na revisão.

\begin{tabular}{|c|c|c|c|c|c|}
\hline $\begin{array}{l}\text { Autores/ano/ } \\
\text { país }\end{array}$ & Tipo de estudo & $\begin{array}{l}\text { Participantes } \\
\text { (n)/ Idade }\end{array}$ & Intervenção & Principais resultados & $\begin{array}{l}\text { Avalição } \\
\text { dos } \\
\text { artigos }\end{array}$ \\
\hline $\begin{array}{l}\text { Paparo et al., } \\
(2019) \\
\text { Itália. }\end{array}$ & $\begin{array}{l}\text { Ensaio clínico } \\
\text { randomizado, } \\
\text { controlado }\end{array}$ & $\begin{array}{l}\mathrm{n}=30 \\
2 \mathrm{a} 4 \text { meses }\end{array}$ & $\begin{array}{l}\text { Fórmula extensamente hidrolisada } \\
\text { contendo Lactobacillus rhamnosus. } \\
\text { Fórmula à base de soja } \\
\text { Duração de } 12 \text { meses }\end{array}$ & $\begin{array}{l}\text { Houve uma modulação mais forte dos } \\
\text { mecanismos epigenéticos associados a } \\
\text { uma tendência de maior taxa de aquisição } \\
\text { de tolerância imunológica em crianças } \\
\text { tratadas com a fórmula extensamente } \\
\text { hidrolisada } \\
\text { rhamnosus. }\end{array}$ & CASP: 6 \\
\hline $\begin{array}{l}\text { Convidado; } \\
\text { Fuller (2019). } \\
\text { Reino Unido }\end{array}$ & $\begin{array}{l}\text { Estudo de coorte } \\
\text { retrospectiva }\end{array}$ & $\begin{array}{l}\mathrm{n}=470 \\
\text { Média de idade } \\
5,2 \text { meses }\end{array}$ & $\begin{array}{l}\text { Fórmula extensamente hidrolisada } \\
\text { com Lactobacillus rhamnosus. } \\
\text { Fórmula com soro do leite. } \\
\text { Duração de } 24 \text { meses }\end{array}$ & $\begin{array}{l}\text { A fórmula extensamente hidrolisada } \\
\text { com Lactobacillus rhamnosus retardou a } \\
\text { marcha alérgica observada em crianças } \\
\text { alérgicas ao leite de vaca. }\end{array}$ & CASP: 8 \\
\hline $\begin{array}{l}\text { Inuo et al., } \\
(2018) \text {. } \\
\text { Japão }\end{array}$ & $\begin{array}{l}\text { Ensaio clínico } \\
\text { randomizado, } \\
\text { duplo-cego } \\
\text { controlado }\end{array}$ & $\begin{array}{l}\mathrm{n}=25 \\
\text { Média de idade } \\
\text { de } 4,25 \text { anos. }\end{array}$ & $\begin{array}{l}\text { Fórmula extensamente hidrolisada. } \\
\text { Fórmula à base de aminoácidos. } \\
\text { Fórmula de leite de vaca normal. } \\
\text { Duração de } 16 \text { semanas. }\end{array}$ & $\begin{array}{l}\text { A imunoterapia oral envolvendo a } \\
\text { ingestão de fórmula extensamente } \\
\text { hidrolisada melhorou a tolerância ao leite } \\
\text { de vaca em crianças com APLV. }\end{array}$ & CASP: 6 \\
\hline $\begin{array}{l}\text { Candy et al., } \\
\text { (2018). } \\
\text { Londres, Reino } \\
\text { Unido, Itália, } \\
\text { Bélgica e Suécia }\end{array}$ & $\begin{array}{l}\text { Ensaio clínico } \\
\text { duplor cego } \\
\text { randomizado, } \\
\text { controlado, } \\
\text { multicêntrico }\end{array}$ & $\begin{array}{l}\mathrm{n}=71 \\
\text { Média de } 5,67 \\
\text { meses }\end{array}$ & $\begin{array}{l}\text { Fórmula à base de aminoácidos com } \\
\text { simbióticos (prebióticos de } \\
\text { frutooligossacarídeos e a cepa } \\
\text { probiótica Bifidobacterium breve M- } \\
16 \mathrm{~V} \text { ). } \\
\text { Fórmula à base de aminoácidos sem } \\
\text { simbióticos. } \\
\text { Duração de } 8 \text { semanas. }\end{array}$ & $\begin{array}{l}\text { Fórmula à base de aminoácidos incluindo } \\
\text { simbióticos melhorou a microbiota fecal } \\
\text { de bebês com suspeita de APLV. }\end{array}$ & CASP: 7 \\
\hline $\begin{array}{l}\text { Scalabrin et al., } \\
\text { (2017). } \\
\text { Estados Unidos }\end{array}$ & $\begin{array}{l}\text { Ensaio clínico } \\
\text { duplo-cego, } \\
\text { controlado, } \\
\text { prospectivo e } \\
\text { multicêntrico }\end{array}$ & $\begin{array}{l}\mathrm{n}=183 \\
3 \text { a } 5 \text { anos }\end{array}$ & $\begin{array}{l}\text { Fórmula extensamente hidrolisada. } \\
\text { Fórmula extensamente } \\
\text { com hidrolisada } \\
\text { (LGG). } \\
\text { Fórmula à base de aminoácidos com } \\
\text { LGG. } \\
\text { Duração de } 12 \text { meses }\end{array}$ & $\begin{array}{l}\text { As fórmulas que usaram Lactobacillus } \\
\text { rhamnosus foram associadas a } \\
\text { crescimento e desenvolvimento normais } \\
\text { de crianças com APLV e segurança em } \\
\text { longo prazo até os } 5 \text { anos de idade. }\end{array}$ & CASP: 7 \\
\hline $\begin{array}{l}\text { Vanderhoof, } \\
\text { Moore, \& } \\
\text { Boissieu (2016). } \\
\text { França }\end{array}$ & $\begin{array}{l}\text { Estudo } \\
\text { observacional, } \\
\text { prospectivo, } \\
\text { multicêntrico }\end{array}$ & $\begin{array}{l}\mathrm{n}=30 \\
1 \text { a } 12 \text { meses }\end{array}$ & $\begin{array}{l}\text { Fórmula infantil à base de } \\
\text { aminoácidos. } \\
\text { Duração de } 12 \text { semanas }\end{array}$ & $\begin{array}{l}\text { Diminuiu a gravidade da dermatite } \\
\text { atópica. }\end{array}$ & CASP: 8 \\
\hline $\begin{array}{l}\text { Harvey et al., } \\
\text { (2017). } \\
\text { Reino Unido }\end{array}$ & $\begin{array}{l}\text { Ensaio clínico, } \\
\text { randomizado, } \\
\text { duplo-cego } \\
\text { controlado, } \\
\text { prospectivo }\end{array}$ & $\begin{array}{l}\mathrm{n}=110 \\
0 \text { a } 8 \text { meses. }\end{array}$ & $\begin{array}{l}\text { Fórmula a base de aminoácidos com } \\
\text { e sem simbióticos. } \\
\text { Duração: } 16 \text { semanas }\end{array}$ & $\begin{array}{l}\text { Ambas as fórmulas foram eficazes em } \\
\text { fornecer um estado mineral (cálcio, } \\
\text { fósforo, cloreto, sódio, potássio, magnésio } \\
\text { e ferro (ferritina) adequado de bebês. }\end{array}$ & CASP: 8 \\
\hline $\begin{array}{l}\text { Canani et al., } \\
(2016) .\end{array}$ & $\begin{array}{l}\text { Ensaio clínico, } \\
\text { randomizado, } \\
\text { controlado }\end{array}$ & $\begin{array}{l}\mathrm{n}=220 \\
\text { Média de idade } \\
\text { de } 5,0 \text { meses }\end{array}$ & $\begin{array}{l}\text { Fórmula extensamente hidrolisada; } \\
\text { Fórmula extensamente hidrolisada } \\
\text { contendo o probiótico Lactobacillus } \\
\text { rhamnosus (LGG). } \\
\text { Duração: } 36 \text { meses. }\end{array}$ & $\begin{array}{l}\text { A fórmula com probióticos foi mais eficaz } \\
\text { na prevenção da ocorrência de outras } \\
\text { alergias alimentares e acelerou o } \\
\text { desenvolvimento de tolerância oral em } \\
\text { crianças APLV. }\end{array}$ & CASP: 8 \\
\hline $\begin{array}{l}\text { Dupont et al., } \\
\text { (2016). } \\
\text { França }\end{array}$ & $\begin{array}{l}\text { Estudo } \\
\text { multicêntrico } \\
\text { prospectivo }\end{array}$ & $\begin{array}{l}\mathrm{n}=30 \\
\text { Idade de } 1 \text { a } 12 \\
\text { meses. }\end{array}$ & $\begin{array}{l}\text { Fórmula extensamente hidrolisada à } \\
\text { base de caseína como fonte de } \\
\text { proteína e é engrossada com um } \\
\text { complexo patenteado contendo fibras } \\
(0,5 \mathrm{~g} / 100 \mathrm{ml}) \text {, compostas } \\
\text { principalmente de pectina. }\end{array}$ & $\begin{array}{l}\text { Os sintomas digestivos foram resolvidos } \\
\text { ou melhorados a partir do dia } 14 \text { para } \\
83,3 \% \text { dos pacientes e para } 100 \% \text { dos } \\
\text { pacientes em } 45 \text { dias. } \\
\text { Foi observado a normalização do } \\
\text { crescimento dos bebês de acordo com os }\end{array}$ & CASP: 6 \\
\hline
\end{tabular}




\begin{tabular}{|c|c|c|c|c|c|}
\hline & & & & Duração: 4 meses. & padrões da OMS. \\
\hline $\begin{array}{l}\text { Dupont, Hol, \& } \\
\text { Nieuwenhuis, } \\
\text { (2015). } \\
\text { Holanda }\end{array}$ & $\begin{array}{l}\text { estudo } \\
\text { randomizado, } \\
\text { duplo-cego } \\
\text { controlado } \\
\text { placebo }\end{array}$ & $\begin{array}{r}\mathrm{e} \\
\text { por }\end{array}$ & $\begin{array}{l}\mathrm{N}=119 \\
\text { A idade média } \\
\text { foi de } 4,2 \\
\text { meses }\end{array}$ & $\begin{array}{l}\text { Fórmula extensamente hidrolisada à } \\
\text { base de caseína } \\
\text { Lactobacillus paracasei CASEI } \\
431 \circledR \\
\text { Bifidobacterium lactis BB-12@ } \\
\text { Duração: } 6 \text { meses }\end{array}$ & $\begin{array}{l}\text { o presente estudo mostrou que a fórmula CASP: } 6 \\
\text { foi bem tolerado e permitiu uma } \\
\text { recuperação do crescimento em crianças } \\
\text { alérgicas a alimentos com } \\
\text { baixo crescimento } \\
\text { recomendam fórmulas à base de } \\
\text { aminoácidos principalmente em caso } \\
\text { de intolerância a fórmulas extensivamente } \\
\text { hidrolisadas }\end{array}$ \\
\hline $\begin{array}{l}\text { Vandenplas, et } \\
\text { al. (2014). } \\
\text { Bélgica, Grécia, } \\
\text { Kuwait, Líbano } \\
\text { e Eslovênia }\end{array}$ & $\begin{array}{l}\text { Estudo } \\
\text { prospectivo, } \\
\text { randomizado } \\
\text { duplo-cego }\end{array}$ & $\mathrm{e}$ & $\begin{array}{l}72 \text { bebês } \\
6 \text { meses de } \\
\text { idade }\end{array}$ & $\begin{array}{l}\text { Fórmula de caseína extensamente } \\
\text { hidrolisada } \\
\text { Duração: } 1 \text { mês }\end{array}$ & $\begin{array}{l}\text { Reduziu episódios de regurgitação e } \\
\text { melhoraram os sintomas cutâneos } \\
\text { respiratórios. }\end{array}$ \\
\hline
\end{tabular}

Critical Apppraisal Skills Programme (CASP). Fonte: Autores (2021)

\section{Discussão}

Esta revisão sistemática foi conduzida a fim de investigar o efeito de fórmulas nutricionais em crianças com APLV. Ressalta-se que todos os dos estudos mostraram melhoras nos sintomas relacionados a alergia e 6 deles tiveram resultados também satisfatórios quando associados aos probióticos.

Os resultados observados neste estudo demonstram que as fórmulas testadas atendem aos critérios da American Academy of Pediatrics (AAP) para fórmula hipoalergênica, que deve ser tolerado pela maior parte das crianças. Este estudo mostra que as crianças tratadas com fórmulas hidrolisadas associadas ou não aos probióticos mostraram melhor tolerância e melhoras dos sintomas gastrointestinais.

Os probióticos são microrganismos vivos que, quando administrados em quantidades adequadas, proporcionam um benefício à saúde do hospedeiro (Hill, et al., 2014). Os mecanismos de ação incluem colonização transitória do trato intestinal (Eloe-Fadrosh, 2015; Petschow, et al., 2005), aumento de citocinas antiinflamatórias e estabilização de junções apertadas no intestino (Johnson-Henry, 2005) Lactobacillus rhamnosus GG (LGG), que foi o probiótico mais utilizado nos estudos dessa revisão, atua não apenas na mucosa intestinal do hospedeiro, por meio de adesão e interações imunomoduladoras (Lebeer, et al., 2012), mas também estimula vias antiinflamatórias e a produção de butirato nas bactérias residentes no intestino (Hill, et al., 2014; Berni, et al.,2016).

A associação da fórmula extensamente hidrolisada contendo Lactobacillus rhamnosus tem efeitos positivos na disbiose intestinal, produção de ácidos graxos de cadeia curta e na regulação epigenética da expressão gênica de citocinas (Berni, et al., 2015). Esses mecanismos sugerem um possível efeito de longo prazo no sistema imunológico de crianças com APLV, algo importante pois embora a alergia alimentar seja uma condição crônica comum na infância, estudos recentes sugerem que a história natural da alergia alimentar mudou com aumento da prevalência, gravidade das manifestações clínicas e risco de persistência em idades posteriores (Skripak, et al., 2007; Mcbride, et al., 2012).

O ESPGHAN (The European Society for Pediatric Gastroenterology, Hepatology and Nutrition) e o Consenso da ASBAI divergem com relação ao uso de probióticos para prevenção da alergia. ASBAI defende o uso da cepa: Lactobacillus rhamnosus, como sendo importante para a prevenção, ao passo que o ESPGHAN, comenta que não há consenso sobre o uso de probióticos e prebióticos na prevenção de alergia alimentar (Brasil, 2008; Koletzko, 2012).

As doenças alérgicas são parcialmente determinadas por uma interação entre fatores genéticos e ambientais durante o início da vida, com um papel importante desempenhado pela microbiota intestinal e pela epigenética. Dentre os mecanismos epigenéticos potencialmente responsáveis pelo desenvolvimento de doenças alérgicas, a metilação do DNA é o mais proeminente e extensamente investigado (Weinmann, et al., 2017). O tipo de fórmula utilizado tem papel importante, pois pode modular vias envolvidas nos mecanismos epigenéticos que conduzem à alergia ao leite de vaca. 
Além da combinação das fórmulas com probióticos, dois dos estudos incluídos nessa revisão utilizaram a fórmula com simbióticos. Os simbióticos possuem propriedades probióticas e prebióticas e foram criados para superar algumas possíveis dificuldades na sobrevivência dos probióticos no trato gastrointestinal (Rioux, et al.,2005), além disso eles atuam na estimulação da proliferação de cepas bacterianas nativas específicas presentes no trato gastrointestinal (Gourbeyre et al., 2011).

Dos estudos realizados apenas um foi com fórmula à base de soja. $\mathrm{O}$ uso de fórmulas à base de proteína de soja para a alergia ao leite de vaca é controverso. Em geral, não se aconselha introduzir um novo alimento, como a soja, em pacientes com barreira da mucosa intestinal ativamente inflamada e lesada por pelos menos um mês, pois o alérgeno promove uma reação inflamatória na mucosa. Em consequência dessa inflamação, ocorre aumento adicional da permeabilidade da mucosa, que já é mais permeável pela própria imaturidade gastrointestinal dos lactentes, com maior penetração de macromoléculas, perpetuação do processo inflamatório e, na maioria das vezes, com aparecimento de sensibilidade também para a proteína da soja (Pereira, \& Silva, 2008).

As fórmulas à base de soja são indicadas para tratamento de alergia à proteína do leite de vaca IgE mediada (à partir de 6 meses), intolerância à lactose, galactosemia, e opção familiar (vegetarianos ou vegans). Por apresentarem fitatos que atrapalham absorção e diminuem a biodisponibilidade de ferro e zinco, as fórmulas de soja, são suplementadas desses minerais, além de cálcio e fósforo, objetivando a adequada mineralização óssea (Yonamine, et al., 2011). Além de fitatos, a soja também possui alto teor de alumínio e fitoestrógeno (representado na soja pela classe das isoflavonas, genisteína e daidzeína). Estudos guardam relação entre alto teor de fitoestrógeno e efeito no desenvolvimento sexual e reprodutivo (Agostini, et al., 2006), porém, são necessários mais trabalhos sobre os efeitos adversos do uso da soja em longo prazo (Yonamine, et al., 2011).

O melhor tratamento dietoterápico para os lactentes com APLV é sempre o leite materno, porém caso não seja possível, deve-se usar as fórmulas infantis (Delgado, et al., 2010). As fórmulas infantis mais frequentemente prescritas em lactentes alérgicos consistem de hidrolisados de caseína ou de soro de leite. Fórmulas à base de proteína de leite de vaca totalmente ou extensamente hidrolisada são quase sempre eficazes (97\%) em lactentes com alergia à proteína do leite de vaca de início imediato ou tardio (Ferreira \& Seidman, 2007). Entretanto, nenhuma das fórmulas hidrolisadas está completamente livre de alérgenos e reações graves raras às fórmulas extensamente hidrolisadas já foram descritas. Em casos graves resistentes ao tratamento com fórmula totalmente hidrolisada ou em pacientes com alergias alimentares múltiplas, são necessárias fórmulas à base de aminoácidos livres (Brasil, 2008).

Embora as fórmulas totalmente hidrolisadas pareçam auxiliar na prevenção da alergia ao leite, problemas relacionados ao seu custo e palatabilidade levaram à criação de fórmulas parcialmente hidrolisadas. O objetivo de desenvolver esse tipo de produto foi tentar prevenir a sensibilização primária de lactentes e ao mesmo tempo estimular a tolerância oral aos antígenos do leite. Outras possíveis vantagens das fórmulas parcialmente hidrolisadas em relação às extensamente hidrolisada, no tocante à prevenção, são suas propriedades organolépticas melhores, bem como seu custo mais baixo (Ferrera \& Seidman, 2007).

Como limitações dessa revisão sistemática é importante destacar as diferenças nos protocolos de uso das fórmulas, nem todos os estudos especificaram a quantidade de fórmula utilizada, tiveram também variação na duração de tempo de intervenção, parâmetros de avaliação e localização geográfica.

Por isso são necessários novos estudos, principalmente controlados e também longitudinais para elucidar por exemplo, mecanismos epigenéticos associados ao uso de fórmulas nutricionais e acompanhar crianças com APLV à longo prazo e verificar se não apresentarão novas alergias. Este estudo contribui para subsidiar novas pesquisas e embasar estudos relacionados ao uso de fórmulas nutricionais mais eficazes no tratamento da APLV. 


\section{Conclusão}

A presente revisão demostra que todos os tipos de fórmulas analisadas nos estudos contribuíram para melhora nos sintomas relacionados a alergia a proteína do leite de vaca, sendo os melhores resultados observados para as fórmulas adicionadas de probióticos.

Com base na literatura analisada, as fórmulas contendo Lactobacilos rhamnosus estão associadas com crescimento e desenvolvimento normais das crianças. As fórmulas contendo esse probiótico também foram associadas a menor risco de desenvolvimento de outras alergias e redução de manchas vermelhas em crianças. Já quando se comparou duas fórmulas a base de aminoácidos livres com e sem simbióticos, a formula contendo simbióticos melhorou a microflora fecal das de crianças e ambas as fórmulas foram eficazes no fornecimento de um estado mineral adequado. As fórmulas a base de aminoácidos se associaram a melhora nos sintomas alérgicos, como diminuições na gravidade da dermatite atópica. Já fórmulas extensamente hidrolisadas reduziram sintomas digestivos e ainda melhorou a tolerância ao leite de vaca.

Ressalta-se a necessidade de mais estudos que avaliem os efeitos dos probióticos adicionados em fórmulas nutricionais para o tratamento de APLV, seu potencial precisa ser melhor avaliado, principalmente em estudos a longo prazo.

\section{Referências}

Aguiar, A. L. O. (2013). Avaliação clínica e evolutiva de crianças em programa de ate. Rev Paul Pediatr, 31 (2), $152-8.10 .1590 /$ S0103-05822013000200004.

Barros, K.V. et al. (2017). Evidence for Involvement of IL-9 and IL-22 in Cows' Milk Allergy in Infants. Nutrients, 9 (1040), 1-10. 10.3390/nu9101048.

Berni, R. et al. (2015). Differences in DNA methylation profile of Th1and Th2 cytokine genes are associated with tolerance acquisition in children with IgEmediated cow's milk allergy. Clin Epigenet. 7 (1), 1-9. 10.1186/s13148-015-0070-8.

Berni, R.et al. (2016). Lactobacillus rhamnosus GG supplemented formula expands butyrate producing bacterial strains in food allergic infants. ISME J.10 (1), 742-750. 10.1038/ismej.2015.151.

Brasil (2008). Associação Brasileira de Alergia e Imunopatologia. Consenso brasileiro sobre alergia alimentar: 2007. Revista Brasileira de Alergia e Imunologia, 31 (2), 64-89.

Brasil (2018). Associação Brasileira de Alergia e Imunopatologia. Consenso brasileiro sobre alergia alimentar: 2007. Arquivos de Asma, Alergia e Imunologia, $2(1), 39-82$.

Boettcher, E. \& Crowe, S. E. (2013). Dietary proteins and functional gastrointestinal disorders. Am J Gastroenterol.108 (5), 728-36. $10.1038 / a j g .2013 .97$.

Caetano, M. C., Ortiz, T.T., Silva, S. G. L., Souza F. I. S. \& Sarni, R. O. S. (2010). Alimentação complementar: práticas inadequadas em lactentes. J. Pediatr., 86 (3), 196-201. 10.5123/S1679-49742015000300012.

Canani, R.B. et al. (2017). Extensively hydrolyzed casein formula containing Lactobacillus rhamnosus GG reduces the occurrence of other allergic manifestations in children with cow's milk allergy: 3-year randomized controlled trial. J allergy clin immunol., 139 (6), $1906-1914$. 10.1016/j.jaci.2016.10.050.

Candy, D. C. A., et al. (2018). A synbiotic-containing amino-acid-based formula improves gut microbiota in non-IgE-mediated allergic infants. Pediatr Res., 83 (3), 677-686.10.1038/pr.2017.270.

Dupont, C., Bradatan, E., Soulaine, P., Nocerino, R. \& Berni-Canani, R. (2016). Tolerance and growth in children with cow's milk allergy fed a thickened extensively hydrolyzed casein-based formula. BMC Pediatrics. 16 (96), 1-8. 10.1186/s12887-016-0637-3.

Dupont C., Hol J. \& Nieuwenhuis E. E.S. (2015). An extensively hydrolysed casein-based formula for infants with cows' milk protein allergy: tolerance/hypoallergenicity and growth catch-up. British Journal of Nutrition.113 (1), 1102-1112. 10.1017/S000711451500015X.

Delgado, A. F., Cardoso, A. L. \& Zamberlan, P. (2010). Nutrologia básica e avançada. 1. ed. São Paulo: Manole.

Dupont, C. et al. (2011). Dietary treatment of cows' milk protein allergy in childhood: a commentary by the Committee on Nutrition of the French Society of Paediatrics. Br J Nutr, 107 (1), 325-338. 10.1017/S0007114511004831.

Eloe-Fadrosh, E. A. et al. (2015). Functional dynamics of the gut microbiome in elderly people during probiotic consumption. MBio,1 (1), 6. 10.1128/mBio.00231-15.

Ferreira, C. T. \& Seidman, E. (2007). Alergia alimentar: atualização prática do ponto de vista gastroenterológico. Jornal de Pediatria, 83 (1), 7-20. $10.1590 /$ S0021-75572007000100004.

Fiocchi, A., et al. (2010). World Allergy Organization (WAO) diagnosis and rationale for action against cow's milk allergy (DRACMA) Guidelines. World Allergy Organ J. 3 (4), 57-161. 10.1097/WOX.0b013e3181defeb9. 
Gourbeyre, P., Denery, S.\& Bodinier, M. (2011). Probióticos, prebióticos e simbióticos: Impacto no sistema imunológico do intestino e reações alérgicas. $J$. Leukoc. Biol., 89 (1), 685-695. 10.1590/S0103-05822010000100014.

Harvey, B. M., Eussen, S. R. B. N., Harthoorn, L. F. \& Burks, A. W. (2017). Mineral Intake and Status of Cow's Milk Allergic Infants Consuming an Amino Acid-based Formula. Short communication: nutrition, 65 (3), 346-340. 10.1097/MPG.0000000000001655.

Hill, C. et al. (2014). Expert consensus document. The International Scientific Association for Probiotics and Prebiotics consensus statement on the scope and appropriate use of the term probiotic. Nat. Rev Gastroenterol Hepatol, 11 (8), 506-14. 10.1038/nrgastro.2014.66.

Host, A. \& Halken, S. (2014). Cow's milk allergy: where have we come from and where are we going? Endocr Metab Immune Disord Drug Targets., 14 (1), 2-8. 10.2174/1871530314666140121142900.

Koletzko, S. et al. (2012). Diagnostic approach and management of cow's milk protein allergy in infants and children: ESPGHAN GI Committee pratical guidelines. Journal of Pediatric Gastroenterology and Nutrition, 55 (1), 221-229. 10.1097/MPG.0b013e31825c9482.

Kemp, A. S., et al. (2008). Guidelines for the use of infant formulas to treat cows milk protein allergy: an Australian consensus panel opinion. Med $J$ Aust.188,109-12. 10.5694/j.1326-5377.2008.tb01534.x.

Lebeer S. et al. (2012). Functional analysis of Lactobacillus rhamnosus GG pili in relation to adhesion and immunomodulatory interactions with intestinal epithelial cells. Appl Environ Microbiol.78 (1), 185-193. 10.1128/AEM.06192-11.

London (2002). Milton Keynes Primary Care Trust. Critical Appraisal Skills Programme. London: Oxford.

Manuyakorn, W. \& Tanpowpong, P. (2019). Cow milk protein allergy and other common food allergies and intolerances. Paediatr Int Child Health., 39 (1), 32-40. 10.1080/20469047.2018.1490099.

Mcbride, D. et al., (2012). The EuroPrevall birth cohort study on food allergy: baseline characteristics of 12,000 newborns and their families from nine European countries, Pediatr Allergy Immunol.,23(1), 230-239. 10.1111/j.1399-3038.2011.01254.x.

Paparo, L., et al., (2016). Epigenetic features of FoxP3 in children with cow's milk allergy. Clin Epigenetics.8 (86), 1-8. 10.1186/s13148-016-0252-z.

Petschow, B.W. et al., (2015). Effects of feeding an infant formula containing Lactobacillus GG on the colonization of the intestine: a dose-response study in healthy infants. J Clin Gastroenterol., 39 (1), 86-790, 10.1097/01.mcg.0000177245.53753.86.

Pereira, P. B. \& Silva, C. P. (2008). Alergia a proteína do leite de vaca em crianças: repercussões da dieta de exclusão e da dieta substitutiva sobre o estado nutricional. Revista Pediatria, 30 (2), 100-106.

Reche, M. et al., (2010). O efeito de uma fórmula parcialmente hidrolisada à base de proteína de arroz no tratamento de bebês com alergia à proteína do leite de vaca. Pediatr Allergy Immunol. 21(4), 577-85.

Rioux, K.P. et al. (2005). O papel da microflora entérica na doença inflamatória do intestino: Estudos em humanos e animais com probióticos e prebióticos. Gastroenterol. Clin. N. Am., 34 (1), 465-482.

Skripak, J.M. et al. (2007). The natural history of IgE-mediated cow's milk allergy. J Allergy Clin Immunol., 1 (1), 120. 10.1016/j.jaci.2007.08.023.

Savage, J. \& Johns, C. B. (2014). Food allergy: epidemiology and natural history. Immunol. Allergy Clin. North Am., 35 (1), 45-59.

10.1016/j.iac.2014.09.004.

Scalabrin, D., Harris, C., Johnston, W.H. \& Berseth, C. L. (2017). Long-term safety assessment in children who received hydrolyzed protein formulas with Lactobacillus rhamnosus GG: a 5-year follow-up. Eur J Pediatr., 176 (2), 217-224. 10.1007/s00431-016-2825-4.

Vandenplas, Y. et al. (2007). Guidelines for the diagnosis and management of cow's milk protein allergy in infants. Arch Dis Child. 92, 902-908, 10.1136/adc.2006.110999.

Vandenplas, Y., De Greef, E. \& Hauser, B. (2014). Safety and tolerance of a new extensively hydrolyzed rice protein-based formula in the management of infants with cow's milk protein allergy. Eur J Pediatr.173 (1),1209-1216. 10.1007/s00431-014-2308-4.

Vandenplas Y. et al. (2015). Extensive protein hydrolysate formula effectively reduces regurgitation in infants with positive and negative challenge tests for cow's milk allergy. Acta Paediatr.104, 449-457. 10.1111/apa.12615.

Venter, C., \& Arshad, S. H.(2011). Epidemiology of food allergy. Pediatr. Clin. N. Am., 58 (1), 327-349. /10.1016/j.pcl.2011.02.011.

Yonamine, G. H. et al., (2011). Uso de fórmulas à base de soja na alergia à proteína do leite de vaca. Revista Brasileira de Alergia e Imunopa, 34 (5),187-192. 